OPEN ACCESS

Edited by:

Angel Lanas,

University of Zaragoza, Spain

Reviewed by:

Katsunori lijima,

Tohoku University, Japan

Ruggiero Francavilla,

University of Bari Aldo Moro, Italy

*Correspondence:

Liuqin Jiang

jiangliuqin@163.com

Bixing Ye

nydybx@163.com

Specialty section:

This article was submitted to

Gastroenterology,

a section of the journal

Frontiers in Medicine

Received: 14 November 2020

Accepted: 23 April 2021

Published: 28 May 2021

Citation:

Ye $B$, Wang $Y$, Lin L, Jiang $L$ and

Wang $M$ (2021) Sex-Based Differences in pH Parameters and

Esophageal Impedance of Patients

With Gastroesophageal Reflux

Disease. Front. Med. 8:629302.

doi: 10.3389/fmed.2021.629302

\section{Sex-Based Differences in pH Parameters and Esophageal Impedance of Patients With Gastroesophageal Reflux Disease}

\author{
Bixing Ye*, Yanjuan Wang, Lin Lin, Liuqin Jiang* and Meifeng Wang \\ Department of Gastroenterology, The First Affiliated Hospital of Nanjing Medical University, Nanjing, China
}

Background/Aims: The incidence of reflux esophagitis (RE) has a striking predominance in males. Conversely, non-erosive reflux disease (NERD) is more common in females. This imbalance of gastroesophageal reflux disease (GERD) implies sex-related differences in its pathogenesis. However, limited studies have analyzed the sex-based differences in $\mathrm{pH}$ parameters and esophageal impedance of GERD patients.

Methods: This study evaluated sex-based pathogenesis differences by comparing reflux episodes, mean nocturnal baseline impedance (MNBI) values, and post-reflux swallowinduced peristaltic wave (PSPW) index values of males with GERD and females with GERD using 24-h multichannel intraluminal impedance and $\mathrm{pH}$ monitoring.

Results: We analyzed 181 patients (102 males and 79 females) with GERD. Reflux symptom index (RSI) scores were higher in females than that in males $(P<0.05)$. Males had significantly longer acid exposure times, higher DeMeester scores, and more acid reflux episodes than females $(P<0.05)$. Females had more instances of weakly acidic reflux than males $(P<0.01)$. The PSPW index values of males and females were similar $(P>0.05)$. Compared with females, males had lower MNBI values for the mid and distal esophagus $(P<0.05)$. However, with increasing age, the MNBI values of females decreased more rapidly than those of males. MNBI values of elderly patients of both sexes older than 60 years were similar.

Conclusions: Acid reflux is more likely to occur in males; however, females tend to have more instances of weakly acid reflux. The integrity of the esophageal mucosa is more fragile in males than in females; however, the esophageal mucosal barrier attenuates more rapidly with increasing age in females than in males.

Keywords: gastroesophageal reflux disease, sex, reflux episode, mean nocturnal baseline impedance, post-reflux swallow-induced peristaltic wave index

\section{INTRODUCTION}

Gastroesophageal reflux disease (GERD) is a common gastrointestinal disease that affects all age groups and both sexes, with an estimated worldwide prevalence of $8-33 \%$ (1). Most epidemiologic studies have suggested that the incidence of reflux esophagitis (RE) has a striking predominance in males (2-5). The male-to-female ratio of the RE prevalence 
is 1.2-1.6 (2-5). Moreover, the male-to-female ratios of Barrett's esophagus (BE) and esophageal adenocarcinoma (EAC) are approximately 2:1 and 3-5:1 (3,4). Conversely, non-erosive reflux disease (NERD) and symptomatic GERD are more common in females $(5,6)$. The sex-based imbalance of GERD implies sex-related differences in its pathogenesis.

It is widely accepted that the vital GERD mechanism is an increase in offensive factors (excessive esophageal noxious content exposure) and defects of defensive factors (mucosa injury, impaired esophageal peristalsis, and damaged anti-reflux barrier). Previous studies have suggested that females have less distal esophageal acid exposure than male healthy volunteers and males with GERD $(7,8)$. However, most studies have demonstrated that non-acid reflux, namely weakly acidic reflux and weakly alkaline reflux, also result in esophageal mucosal damage $(9,10)$ and are refractory to proton pump inhibitor (PPI) therapy $(11,12)$. However, the differences in non-acid reflux of males and females with GERD are still ambiguous.

One study reported that the degree of macroscopic damage observed during endoscopy and the manifestation of RE were more severe in males than in females. In fact, dilated intercellular spaces (DIS), which are signs of mucosal injury, have been observed in NERD patients $(10,13)$. However, in NERD patients, it is unclear whether there are similar sex-based differences in mucosa injury. The mean nocturnal baseline impedance (MNBI) is a novel impedance parameter measured by 24$\mathrm{h}$ esophageal multichannel intraluminal impedance and $\mathrm{pH}$ (MII-pH) monitoring. MNBI represents the permeability of the esophageal mucosa. A negative correlation between MNBI values and intercellular spaces in the esophagus has been observed $(14,15)$. Previous studies indicated that MNBI values were lower in RE and NERD patients than in reflux hypersensitivity $(\mathrm{RH})$ patients, functional heartburn $(\mathrm{FH})$ patients, and healthy individuals $(14,16,17)$. Low MNBI values reflect refluxstimulated mucosal impairment, even in the absence of macroscopic damage (18). Therefore, it is possible to use MNBI to study sex-based differences in mucosal impairment in $\mathrm{RE}$ and NERD.

The post-reflux swallow-induced peristaltic wave (PSPW) index, which is another novel impedance parameter detected by 24-h MII-pH monitoring, reflects the reflux-induced chemical clearance (primary peristalsis). Chemical clearance consists of a salivary swallow elicited by an esophago-salivary vagal reflex and delivery of bicarbonate and epidermal growth factor, thereby augmenting the esophageal $\mathrm{pH}$ and hastening repair of refluxinduced mucosal damage. The PSPW index has been reported to efficiently separate GERD patients from healthy individuals (19). Accordingly, the PSPW index was significantly lower in PPIrefractory RE than in healed RE and in PPI-refractory NERD, thus implying that impairment of chemical clearance has a role in the mechanism of reflux-induced esophageal mucosal damage (20). Therefore, a comparison of the PSPW index values of males and females might contribute to clarifying sex-related differences in pathogenesis.

Most studies have focused on sex-based differences in GERD prevalence, symptoms, and response to PPI; however, studies of sex-based differences in $\mathrm{pH}$ parameters and esophageal impedance are rare. Therefore, this study aimed to clarify the different pathogenesis based on sex by comparing reflux episodes, MNBI, and the PSPW index values of males with GERD and females with GERD using 24-h MII-pH monitoring.

\section{METHODS}

\section{Subjects}

Consecutive patients with GERD symptoms who underwent 24h MII-pH monitoring at the Gastrointestinal Motility Center of the First Affiliated Hospital of Nanjing Medical University between January 2011 and December 2019 were retrospectively reviewed during our study. Within 3 months before MII-pH monitoring, patients underwent upper endoscopy to evaluate the esophageal mucosal macroscopic status and exclude other upper gastrointestinal disorders. The severity of RE was graded using the Los Angeles (LA) classification. The baseline symptoms were assessed using the Reflux Disease Questionnaire (RDQ) and Reflux Symptom Index (RSI). The inclusion criteria were as follows: age 18 years or older; symptoms of GERD at least two times per week for the past 6 months; and fulfilled the diagnostic criteria for GERD according to the Lyon Consensus (21) [distal esophageal acid exposure time (AET) $>6 \%$ on $\mathrm{pH}$ impedance monitoring with or without mucosal damage observed during upper endoscopy]. The exclusion criteria were as follows: tumor, peptic ulcer, or other organic lesions observed during endoscopy; history of gastrointestinal surgery; severe organ dysfunction or esophageal motility disorder; and PPI or any antacid medication within 7 days before MII-pH monitoring. The study was approved by the ethics committee of the First Affiliated Hospital of Nanjing Medical University, and all patients provided written informed consent.

\section{MII-pH Monitoring for $24 \mathrm{~h}$}

The esophageal intraluminal impedance and $\mathrm{pH}$ values were measured using an ambulatory MII-pH monitoring system (Given Imaging, Duluth, GA). After calibration in $\mathrm{pH} 4.0$ and $\mathrm{pH} 7.0$ buffer solutions, the MII-pH probe was positioned in the esophageal body with the $\mathrm{pH}$ sensor at $5 \mathrm{~cm}$ and six intraluminal impedance channels ( $\mathrm{Z} 1, \mathrm{Z} 2, \mathrm{Z3}, \mathrm{Z4}, \mathrm{Z} 5$, and $\mathrm{Z6}$, respectively) at $17,15,9,7,5$, and $3 \mathrm{~cm}$ above the lower esophageal sphincter (LES). During the 24-h MII-pH monitoring test, postures, meals, and symptoms were recorded by pressing a button on the data recorder. The impedance-pH tracings were manually assessed by two researchers using the Bioview analysis software program.

\section{Data Analysis \\ Reflux Episodes}

The $\mathrm{pH}$ parameters, including DeMeester score, AET, number of acid reflux episodes, number of prolonged reflux episodes, and duration of the longest reflux episodes, were analyzed. AET was defined as the total time when $\mathrm{pH}$ was $<4$ in the distal esophagus divided by the total duration of MII-pH monitoring; $\mathrm{pH}<4$ for more than $5 \mathrm{~min}$ indicated a prolonged reflux episode.

The impedance parameters of liquid and mixed (liquid-gas) reflux episodes were measured to determine acid (nadir $\mathrm{pH}<4$ ), weakly acidic (nadir $\mathrm{pH}$ between 4 and 7 ), and weakly alkaline 
reflux (nadir $\mathrm{pH}>7$ ). Reflux episodes were considered proximal when they extended into or above the channel $15 \mathrm{~cm}$ above the LES.

\section{Post-reflux Swallow-Induced Peristaltic Wave Index}

According to a previous study (17), PSPW was defined as an antegrade $50 \%$ decrease in impedance occurring within $30 \mathrm{~s}$ after a reflux event originating in the most proximal impedance channels and reaching the most distal impedance channel, followed by at least $50 \%$ return to the baseline. The PSPW index value was obtained by dividing the number of PSPW by the number of reflux events.

\section{Mean Nocturnal Baseline Impedance}

MNBI (expressed in ohms) was measured during the night recumbent period at three time points $(\sim 1: 00$ a.m., 2:00 a.m., and 3:00 a.m.) during three 10-min periods to avoid reflux and swallowing. The MNBI was calculated using the three impedance values (22). The proximal, mid, and distal MNBI values were measured at 17 and $15 \mathrm{~cm}$ above the LES ( $\mathrm{Z} 1$ and $\mathrm{Z} 2$ ), at 9 and $7 \mathrm{~cm}$ above the LES ( $\mathrm{Z3}$ and $\mathrm{Z4}$ ), and at 5 and $3 \mathrm{~cm}$ above the LES ( $\mathrm{Z} 5$ and $\mathrm{Z6}$ ), respectively (23).

\section{Statistical Analysis}

Normality of the continuous variables was assessed using the Kolmogorov-Smirnov test or Shapiro-Wilk test, depending on the sample size. If the continuous variables were normally distributed, then they were expressed as mean \pm standard deviation (SD) and compared using the two-tailed Student $t$ test. Otherwise, data were expressed as medians and interquartile ranges (IQR; 25th-75th percentile) and compared using the Mann-Whitney $U$ test. Categorical variables were compared using the $\chi 2$ test or Fisher's exact test. Correlation between MNBI and age, $\mathrm{pH}$-impedance parameters, PSPW index were performed with Pearson's correlation coefficient (two-tailed). Multivariate analyses were performed using linear regression for MNBI values as a dependent variable and the associations of sex, age, reflux episodes, and PSPW index as appropriate. Nonstandardized coefficients $(\beta)$ and $95 \%$ confidence intervals (CI) for each of the variables examined were calculated. Because age is associated with the MNBI, the interaction effects of sex and age on MNBI values were analyzed using a two-way analysis of variance (ANOVA). $P<0.05$ was considered statistically significant. All data were analyzed using SPSS (version 20; IBM Corp., Armonk, NY) and Prism software (version 8; Graph Pad, San Diego, CA).

\section{RESULTS}

\section{Demographics and Clinical Characteristics}

A total of 699 patients were referred for 24-h MII-pH monitoring at our hospital from 2011 to 2019. Among them, 181 patients were finally enrolled in our study, 518 patients were excluded (503 patients with AET $<6 \%$, six patients with cardiac surgery, four patients with peptic ulcer, three patients with achalasia, and two patients with lung transplantation). In 181 GERD patients, there were $102(56.4 \%)$ males and $79(43.6 \%)$ females with ages ranging from 21 to 78 years (mean age, $51.1 \pm$ 12.0 years). Endoscopy revealed that 56 patients had erosive esophageal mucosa (40 with LA grade A and 16 with LA grade B). A total of $120(66.3 \%)$ patients presented with typical symptoms (73 with heartburn and 47 with regurgitation) and 61 presented with atypical symptoms (33 with cough, 16 with chest pain, four with abdominal discomfort, four with belching, and four with dysphagia). RSI scores were higher in females [6.0 IQR (4.0-9.0)] than that in males [4.0 IQR (4.0-8.0)], $P$ $=0.016$. There were no statistically significant differences in age, body mass index (BMI), RE, and RDQ scores of males and females (Table 1).

\section{Reflux Episodes}

When considering sex and $\mathrm{pH}$ parameters, males had significantly longer AET $(P=0.033)$ and higher DeMeester scores $(P=0.03)$ than those of females. More frequent acid reflux episodes, more prolonged acid reflux episodes, and the longest acid reflux episodes occurred in males than in females; however, the differences did not reach significance.

When sex and impedance parameters were examined, males had significantly more acid reflux in the proximal $(P=0.01)$ and distal esophagus $(P=0.001)$. In contrast, females had more instances of weakly acidic reflux in the distal esophagus $(P=$ $0.006)$ than males. There were no significant differences in the number of weakly alkaline reflux episodes in the proximal and distal esophagus and the number of weakly acidic in the proximal esophagus in males and females. The reflux characteristics according to sex are shown in Table 2.

No statistically significant differences in AET, DeMeester scores, number of acid reflux episodes in the distal and proximal esophagus, and number of weakly acidic reflux episodes in the distal esophagus among different age groups were observed (all $P$ $>0.05)$ (Table 3).

TABLE 1 | Demographics and clinical characteristics according to sex.

\begin{tabular}{lccc}
\hline & Males $(\boldsymbol{n}=\mathbf{1 0 2})$ & Females $(\boldsymbol{n}=\mathbf{7 9})$ & $\boldsymbol{P}$-value \\
\hline Age (years) & $49.7 \pm 12.3$ & $52.9 \pm 11.4$ & 0.07 \\
Age groups (years) & & & 0.17 \\
$\leq 40$ & $26(25.5 \%)$ & $11(13.9 \%)$ & \\
$41-50$ & $25(24.5 \%)$ & $19(24.1 \%)$ & \\
$51-60$ & $33(32.4 \%)$ & $27(34.2 \%)$ & \\
$>60$ & $18(17.6 \%)$ & $22(27.8 \%)$ & \\
BMI, kg/m² & $23.7 \pm 3.6$ & $23.2 \pm 2.9$ & 0.28 \\
RE, $n$ (\%) & $36(35.3 \%)$ & $20(25.3 \%)$ & 0.19 \\
Typical symptoms, $n(\%)$ & $73(71.6 \%)$ & $47(59.5 \%)$ & 0.11 \\
RDQ & $10.0(7.0-14.0)$ & $8.0(0-8.0)$ & 0.24 \\
RSI & $4.0(4.0-8.0)$ & $6.0(4.0-9.0)$ & 0.016 \\
\hline
\end{tabular}

Data are presented as mean $\pm S D$, number (percentage) or the median and interquartile range. $B M I$, body mass index; $R E$, reflux esophagitis; $R D Q$, Reflux Disease Questionnaire; RSI, Reflux Symptom Index. 
TABLE 2 | Reflux characteristics according to sex.

\begin{tabular}{|c|c|c|c|}
\hline & Males $(n=102)$ & Females $(n=79)$ & $P$-value \\
\hline \multicolumn{4}{|l|}{ pH PARAMETERS } \\
\hline AET (\%) & $8.3(5.7-13.6)$ & $6.7(1.8-13.0)$ & 0.033 \\
\hline Acid reflux episodes & $95.5(69.0-187.0)$ & $87.0(54.0-134.0)$ & 0.051 \\
\hline Prolonged acid reflux episodes & $4.6(2.0-8.3)$ & $3.0(0-7.0)$ & 0.12 \\
\hline Longest reflux episode (min) & $17.5(8.0-33.0)$ & $11.0(5.0-32.0)$ & 0.13 \\
\hline Distal extent, total & $66.5(41.0-96.3)$ & 85.0 (43.0-117.0) & 0.062 \\
\hline Distal extent, acid & $36(17.8-52.0)$ & $27.0(12.0-41.0)$ & 0.01 \\
\hline Distal extent, weakly acid & $22(7.8-49.0)$ & $43.0(14.0-79.0)$ & 0.006 \\
\hline Distal extent, weakly alkaline & $0(0-2.0)$ & $0(0-3.0)$ & 0.155 \\
\hline Proximal extent, total & $44.0(19.8-78.9)$ & $38.9(19.9-53.9)$ & 0.19 \\
\hline
\end{tabular}

Data are presented as the median and interquartile range. AET, acid exposure time.

TABLE 3 | Reflux characteristics according to age.

\begin{tabular}{|c|c|c|c|c|c|}
\hline & 40 years or younger $(n=37)$ & $41-50$ years $(n=44)$ & $51-60$ years $(n=60)$ & Older than 60 years $(n=44)$ & $P$-value \\
\hline AET (\%) & $6.3(3.5-10.2)$ & $5.7(1.2-13.3)$ & $7.0(3.2-12.6)$ & $8.4(6.4-15.6)$ & 0.088 \\
\hline DeMeester score & $24.2(14.2-40.8)$ & $22.6(7.4-46.5)$ & $26.2(13.1-47.2)$ & $33.0(23.1-62.1)$ & 0.105 \\
\hline Distal extent, acid & $36.0(23.0-54.0)$ & $28.5(15.0-49.5)$ & $33.0(17.0-46.5)$ & $24.0(12.0-50.0)$ & 0.198 \\
\hline Distal extent, weakly acid & $45.0(17.0-77.0)$ & $45.5(16.0-87.0)$ & $38.0(15.5-38.0)$ & $24.0(11.0-33.0)$ & 0.153 \\
\hline Proximal extent, acid & $26.0(15.0-42.0)$ & $18.0(10.9-40.7)$ & $19.9(8.9-31.9)$ & $16.9(8.9-26.0)$ & 0.233 \\
\hline
\end{tabular}

Data are presented as the median and interquartile range. AET, acid exposure time.

\section{Post-reflux Swallow-Induced Peristaltic Wave Index and Mean Nocturnal Baseline Impedance}

There was no significant difference in the PSPW index of males [13.5 IQR (6.1-23.8)] and females [11.7 IQR (3.4-21.6); $P=0.37]$.

All of the MNBI values of six impedance channels were lower in males than in females in GERD, NERD and RE patients, but only MNBI values from Z3 to Z5 in GERD patients $(2,582.6 \pm$ $1,189.4$ ohms vs. $3,554.7 \pm 1,635.7$ ohms, $P<0.001 ; 2,576.9 \pm$ $1,283.3$ ohms vs. $3,292.2 \pm 1,497.7$ ohms, $P=0.001 ; 2,074.3 \pm$ $1,088.3 \mathrm{ohms}$ vs. $2,737.1 \pm 1,448.7 \mathrm{ohms}, P=0.001), \mathrm{MNBI}$ values from Z3 to Z5 in NERD patients $(2,691.5 \pm 1,279.5 \mathrm{ohms}$ vs. $3,594.6 \pm 1,442.7 \mathrm{ohms}, P<0.001 ; 2,682.7 \pm 1,387.0 \mathrm{ohms}$ vs. $3,396.5 \pm 1,332.4 \mathrm{ohms}, P=0.005 ; 2,205.6 \pm 1,164.4 \mathrm{ohms}$ vs. $2,860.5 \pm 1,391.9 \mathrm{ohms}, P=0.007)$, and $\mathrm{MNBI}$ at $\mathrm{Z3}$ in RE patients $(2,389.8 \pm 998.9 \mathrm{ohms}$ vs. $3,441.0 \pm 2,132.7 \mathrm{ohms}, P=$ 0.049) achieved statistical significance (Figure 1).

In addition, MNBI form Z3 to Z5 showed significant correlations with age, AET, prolonged acid reflux episodes, the longest reflux episode, DeMeester score, total reflux in the distal esophagus, weakly acid reflux in the distal esophagus, total reflux in the proximal esophagus and weakly acid reflux in the proximal esophagus (all $P<0.05$ ). The MNBI values associations of age, reflux episodes, and PSPW index are shown in Table 4. After adjusting for above parameters that influenced MNBI values, there were still significant sex-based differences in MNBI values at Z3, Z4, and Z5 $(P<0.05)$. Additionally, age was associated with MNBI values at Z3, Z4, and Z5 $(P<$ 0.05). Multivariate analyses of sex, age, and reflux episodes on MNBI are shown in Table 5. Therefore, the interaction of age and sex with MNBI values was further evaluated. The MNBI values decreased with increasing age in both males and females; however, this decreasing trend occurred more quickly in females than in males. Moreover, an interaction effect was observed for age older than 60 years and sex for MNBI values at Z3 and Z5. MNBI values at Z3 and Z5 in elderly patients older than 60 years were similar for both sexes $(P=0.014$ and 0.044$)$. A more rapid decrease in MNBI values with increasing age occurred in females (Figure 2).

\section{DISCUSSION}

A comprehensive analyses of $\mathrm{pH}$ - impedance tracings, including parameters assessing reflux episodes, primary peristalsis, and mucosal integrity of males and females were performed. The main results of this study were as follows: females had higher 

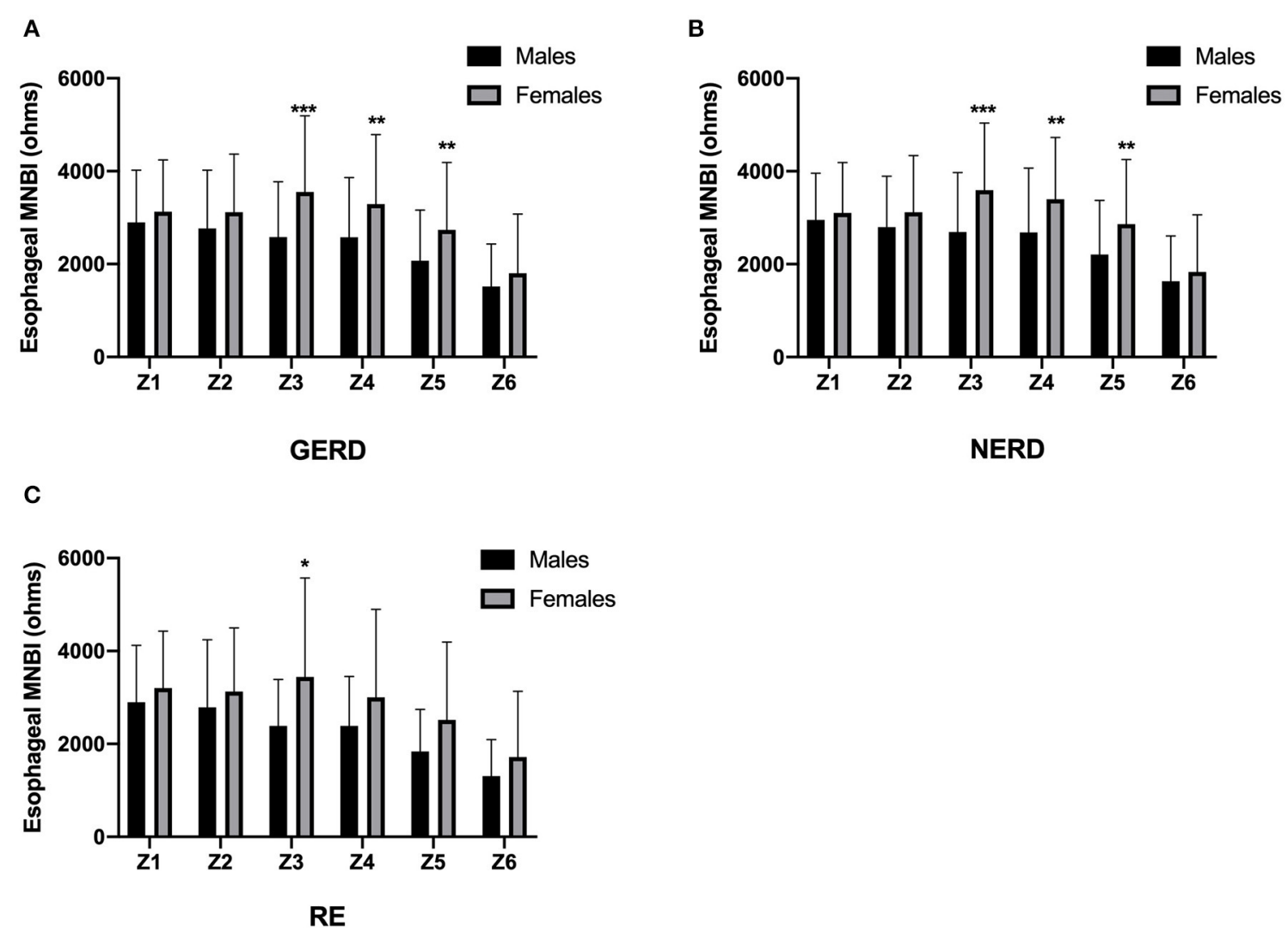

FIGURE 1 | MNBI values from each channel in females and males. MNBI from Z3 to Z5 were lower in males than in females in GERD patients (A) and NERD patients (B), MNBI at Z3 were lower in males than in females in RE patients (C). GERD, gastroesophageal reflux disease; NERD, non-erosive reflux disease; RE, reflux esophagitis; MNBI, mean nocturnal baseline impedance. ${ }^{\star} P<0.05$, ${ }^{\star *} P<0.01$ and ${ }^{\star \star *} P<0.001$ for males and females in each channel.

RSI scores than males; males had significantly longer AET, higher DeMeester scores, and more acid reflux episodes than females; females had more episodes of weakly acidic reflux than males; no statistically significant difference in the PSPW index values of males and females was observed; and males had lower MNBI values at the mid and distal esophagus. However, with increasing age, the MNBI values decreased more rapidly in females than in males.

Many studies have shown a difference in symptom manifestation between females and males with GERD. Previous studies showed that the severity of symptoms in females was significantly more than in males (24), meanwhile, extraesophageal / atypical symptoms were found to be significantly more common in females than in males (25). Similar with previous studies, our study suggested that RSI scores, reflected severity of laryngopharyngeal reflux, were higher in females than in males. It suggested that females had more severe extra-esophageal symptoms. The visceral hypersensitivity, associated with peripheral sensitization, central sensitization, and psycho-neuroimmune interactions, might cause females to be more susceptible to GERD symptoms than males (3). Further studies are warranted to elucidate the mechanisms responsible for sex and gender differences in symptom perception. Moreover, differential sensitivity and enhanced symptoms in females were regarded to have wide diagnostic and therapeutic implications. For example, it is possible that females present to medical treatment earlier in the course of GRED, and may not develop complications, such as BE and EAC (24).

One study found no difference in the reflux episodes of males and females (24). In contrast, several studies reported that males have higher exposure to distal esophageal acid than female healthy volunteers and females with $\operatorname{GERD}(7,8)$. Our results were consistent with those of previous studies. Additionally, a new finding of our study was that females had more episodes of weakly acid reflux than males. These results partially explained that the esophageal mucosa in males is more fragile than that in females; this was verified by this study. During both in vitro and in vivo studies $(9,18,26)$, acid reflux has triggered more obvious cellular damage of the esophageal mucosa compared with weakly acid reflux. Our previous study verified that distal MNBI values were inversely correlated with acid exposure (27). Although distal MNBI values were lower in the non-acid reflux group than in the non-reflux group, no significant difference was observed (27). However, most studies indicated that females had 
TABLE 4 | MNBI values associations of age, reflux episodes, and PSPW index.

\begin{tabular}{|c|c|c|c|}
\hline & Z3 (ohms) & Z4 (ohms) & Z5 (ohms) \\
\hline Age (years) & $-0.392^{\star \star \star}$ & $-0.373^{\star \star \star}$ & $-0.286^{\star \star \star}$ \\
\hline AET (\%) & $-0.383^{\star \star \star}$ & $-0.444^{\star \star \star}$ & $-0.465^{\star \star}$ \\
\hline Prolonged acid reflux episodes & $-0.331^{\star \star \star}$ & $-0.346^{\star \star \star}$ & $-0.368^{\star \star \star}$ \\
\hline Longest reflux episode (min) & $-0.282^{\star \star \star}$ & $-0.324^{\star \star \star}$ & $-0.353^{\star \star \star}$ \\
\hline Distal extent, acid & 0.028 & 0.021 & -0.015 \\
\hline Distal extent, weakly acid & $0.413^{\star \star \star}$ & $0.406^{\star \star \star}$ & $0.409^{\star \star \star}$ \\
\hline Distal extent, weakly alkaline & 0.111 & 0.127 & 0.104 \\
\hline Proximal extent, total & $0.190^{*}$ & $0.213^{\star *}$ & $0.235^{\star \star}$ \\
\hline Proximal extent, acid & -0.007 & -0.018 & -0.049 \\
\hline
\end{tabular}

Pearson's correlation coefficient, r. P-values were calculated using Pearson's correlation analysis. ${ }^{*} P<0.05,{ }^{* *} P<0.01$ and ${ }^{* * *} P<0.001$ were considered statistically significant.

TABLE 5 | Multivariate analyses of sex, age, and reflux episodes on MNBI.

\begin{tabular}{|c|c|c|c|c|c|c|}
\hline & \multicolumn{2}{|l|}{$\mathbf{Z 3}$} & \multicolumn{2}{|l|}{$\mathbf{Z 4}$} & \multicolumn{2}{|l|}{$\mathbf{Z 5}$} \\
\hline Age & $-46.1(-61.1--31.1)$ & $<0.001$ & $-40.3(-55.3--25.3)$ & $<0.001$ & $-26.9(-40.9--12.8)$ & $<0.001$ \\
\hline AET & $-40.9(-90.5-8.6)$ & 0.105 & $-50.9(-99.8--2.1)$ & 0.041 & $-31.6(-77.4--14.1)$ & 0.174 \\
\hline Prolonged acid reflux episodes & $-6.2(-31.1-18.5)$ & 0.619 & $2.8(-21.4-27.1)$ & 0.817 & $-0.8(-23.6-22.0)$ & 0.944 \\
\hline DeMeester score & $5.1(-9.5-19.67)$ & 0.490 & $4.9(-9.5-19.3)$ & 0.504 & $0.5(-13.0-13.9)$ & 0.947 \\
\hline Distal extent, total & $3.2(-8.2-14.6)$ & 0.581 & $8.3(-2.9-19.5)$ & 0.147 & $5.2(-5.3-15.7)$ & 0.330 \\
\hline Distal extent, weakly acid & $3.1(-11.2-17.4)$ & 0.669 & $-4.8(-18.7-9.3)$ & 0.501 & $-3.3(-16.5-9.8)$ & 0.619 \\
\hline Proximal extent, total & $-6.2(-23.1-10.7)$ & 0.468 & $-16.1(-32.7-0.5)$ & 0.058 & $-14.8(-30.4-0.8)$ & 0.063 \\
\hline Proximal extent, weakly acid & $3.4(-22.1-28.9)$ & 0.793 & $20.7(-4.3-0.6)$ & 0.104 & $25.5(2.1-49.1)$ & 0.033 \\
\hline
\end{tabular}

$\beta$, non-standardized coefficients; $\mathrm{Cl}$, confidence intervals.



FIGURE 2 | MNBI values at different ages based on sex. MNBI values decreased with increasing age in both males and females, and an interaction effect was observed for age and sex with MNBI values at Z3 (A) and Z5 (C), but not at Z4 (B). MNBI, mean nocturnal baseline impedance. ${ }^{\star} P<0.05$ and ${ }^{* \star} P<0.01$ for males and females in each age group. 
a poorer response to PPI treatment than males (28-31). The role of non-acid reflux in persistent symptoms in patients with PPI failure has been elucidated. Hence, we speculated that sex-related differences in reflux episodes might cause refractoriness to PPI in females.

The majority of gastroesophageal reflux is removed by volume clearance (secondary peristaltic waves). However, for the complete removal of refluxate, chemical clearance is most often necessary. A recent study (32) showed that the PSPW index was related to the peristaltic reserve of the esophageal smooth muscle evaluated by multiple rapid swallows. Despite conflicting results, several studies reported that esophageal motility was different in male and female healthy participants and male and female GERD patients (33). For instance, one study showed that females had higher LES resting pressures than males (34). On the contrary, other studies reported that no sex-based difference in LES resting pressures were observed $(24,35)$. In our study, there were no significant sex-based differences in the PSPW index; this had not been studied previously. This result indicated that no sex-based differences in esophagus peristalsis exist; however, more studies are required to confirm this finding.

The predominance of RE in males implied that the esophageal mucosa in males is more vulnerable to refluxed gastroduodenal contents. As expected, our study clarified the lower MNBI values of males with GERD. However, the frequencies of $\mathrm{RE}$ and moderate to severe RE increased more rapidly in menopausal females than in males $(2,5)$; therefore, the incidence of RE for females was similar to that for males at age 90 years (2) or at ages older than 70 years (5). Consistent with these results, our study showed that MNBI values decreased more rapidly in females than in males with increasing age. The decrease in estrogen levels during menopause might have a crucial role in the attenuation of the mucosal barrier. Recent studies of experimental animal models have demonstrated that estrogen protects the esophageal mucosal barrier by anti-inflammatory activity (36), inhibition of oxidative stress (37), and expression of tight junction proteins (38). A few studies have reported that hormone replacement therapy (HRT) administered to menopausal females inhibited the esophageal inflammation of GERD and the risk of EAC (39). However, HRT has been shown to increase the risk of GERD symptoms (40). This result was not applicable to the direct administration of estrogen as a therapeutic reagent for GERD. In the future, several molecules of the estrogen signaling pathway may be a target for menopausal females with PPIrefractory GERD.

There were some limitations to our study. First, this was a retrospective database study. There were no available data regarding the potentially etiological factors of GERD, including drinking alcohol, smoking, Helicobacter pylori status, and psychological disorders. If these risk factors were different in females and males, then they might have contributed to the study findings which may be subject to information bias. Second, because the analyzed parameters were reflux episodes, esophageal primary peristalsis, and the mucosal barrier, which are common mechanisms of RE and NERD, we did not stratify GERD into NERD and RE for their respective analyses. However, because the mechanisms of NERD and RE have subtle differences, it might be better to compare sex-based differences in RE and NERD. Third, when we divided the patients into different age groups, the numbers of patients in each group were relatively small; therefore, a statistical bias might have existed.

In conclusion, females had more severe extra-esophageal symptoms, acid reflux is more likely to occur in males, and weakly acid reflux tends to occur more frequently in females. The integrity of the esophageal mucosa is more fragile in males than in females; however, the esophageal mucosal barrier was attenuated more rapidly with increasing age in females than in males. These results offer some evidence that the pathogenesis is different between males and females, and that estrogen is a potentially protective factor of the esophageal mucosa. However, the detailed mechanism of estrogen in controlling the pathogenesis of the GERD spectrum remains to be studied in the future.

\section{DATA AVAILABILITY STATEMENT}

The raw data supporting the conclusions of this article will be made available by the authors, without undue reservation.

\section{ETHICS STATEMENT}

The studies involving human participants were reviewed and approved by ethics committee of the First Affiliated Hospital of Nanjing Medical University. Written informed consent to participate in this study was provided by the participants' legal guardian/next of kin. Written informed consent was obtained from the individual(s) for the publication of any potentially identifiable images or data included in this article.

\section{AUTHOR CONTRIBUTIONS}

BY, YW, LL, and LJ conceptualized the idea for this study. BY and YW performed the analysis and prepared the display items. MW performed esophageal 24-h MII-pH monitoring and analyzed the MII-pH parameters. BY wrote the first draft of the manuscript. LJ revised the manuscript. All authors contributed to the article and approved the submitted version.

\section{FUNDING}

This work was supported by a grant from the National Natural Science Foundation of China (no. 81900485) to BY.

\section{ACKNOWLEDGMENTS}

We are thankful to the staff of the Department of Gastroenterology of the First Affiliated Hospital of Nanjing Medical University, China, for making summary results publicly available. We give special thanks to Professors Hongjie Zhang for guiding the performance of the 24-h MII-pH monitoring. 


\section{REFERENCES}

1. El-Serag HB, Sweet, S, Winchester CC, Dent J. Update on the epidemiology of gastroesophageal reflux disease: a systematic review. Gut. (2014) 63:87180. doi: 10.1136/gutjnl-2012-304269

2. Menon, S, Jayasena H, Nightingale $P$, Trudgill NJ. Influence of age and sex on endoscopic findings of gastrooesophageal reflux disease: an endoscopy database study. Eur $J$ Gastroenterol Hepatol. (2011) 23:389-95. doi: 10.1097/MEG.0b013e328 $345 \mathrm{~d} 429$

3. Kim, S Y, Kim N, Kim GH. Sex and gender differences in gastroesophageal reflux disease. J Neurogastroenterol Motil. (2016) 22:575-88. doi: 10.5056/jnm16138

4. Asanuma K, Iijima K, Shimosegawa T. Gender difference in gastro-esophageal reflux diseases. World J Gastroenterol. (2016) 22:1800-10. doi: 10.3748/wjg.v22.i5.1800

5. Kim SY, Jung HK, Lim J, Kim TO, Choe, Tae AR CH, et al. Gender specific differences in prevalence and risk factors for gastro-esophageal reflux disease. J Korean Med Sci. (2019) 34:e158. doi: 10.3346/jkms. 2019.34.e158

6. Lee SW, Lee TY, Lien HC, Yang SS, Yeh HZ, Chang CS. Characteristics of symptom presentation and risk factors in patients with erosive esophagitis and nonerosive reflux disease. Med Princ Pract. (2014) 23:4604. doi: 10.1159/000363661

7. Vega KJ, Langford-Legg T, Palacio C, Watts J, Jamal MM. Females without reflux symptoms or gastroesophageal reflux disease have less distal esophageal acid exposure than males without reflux symptoms or gastroesophageal reflux disease. Dis Esophagus. (2013) 26:246-9. doi: 10.1111/j.1442-2050.2012.01367.x

8. Ter RB, Johnston BT, Castell DO. Influence of age and gender on gastroesophageal reflux in symptomatic patients. Dis Esophagus. (1998) 11:106-8. doi: 10.1093/dote/11.2.106

9. Farré R, van Malenstein H, De Vos R, Geboes K, Depoortere I, Vanden Berghe $\mathrm{P}$, et al. Short exposure of oesophageal mucosa to bile acids, both in acidic and weakly acidic conditions, can impair mucosal integrity and provoke dilated intercellular spaces. Gut. (2008) 57:1366-74. doi: 10.1136/gut.2007.141804

10. Farré R, Fornari F, Blondeau K, Vieth M, De Vos R, Bisschops R, et al. Acid and weakly acidic solutions impair mucosal integrity of distal exposed and proximal non-exposed human oesophagus. Gut. (2010) 59:1649. doi: 10.1136/gut.2009.194191

11. Mainie I, Tutuian R, Shay S, Vela M, Zhang X, Sifrim D, et al. Acid and non-acid reflux in patients with persistent symptoms despite acid suppressive therapy: a multicentre study using combined ambulatory impedance-pH monitoring. Gut. (2006) 55:1398-402. doi: 10.1136/gut.2005. 087668

12. Frazzoni M, Piccoli M, Conigliaro R, Manta R, Frazzoni L, Melotti G, et al. Refractory gastroesophageal reflux disease as diagnosed by impedance-pH monitoring can be cured by laparoscopic fundoplication. Surg Endosc. (2013) 27:2940-6. doi: 10.1007/s00464-013-2861-3

13. van Malenstein H, Farré R, Sifrim DE. esophageal dilated intercellular spaces (dis) and nonerosive reflux disease. Am J Gastroenterol. (2008) 103:10218. doi: 10.1111/j.1572-0241.2007.01688.x

14. Kandulski A, Weigt J, Caro C, Jechorek D, Wex T, Malfertheiner P. Esophageal intraluminal baseline impedance differentiates gastroesophageal reflux disease from functional heartburn. Clin Gastroenterol Hepatol. (2015) 13:107581. doi: 10.1016/j.cgh.2014.11.033

15. Zhong C, Duan L, Wang K, Xu Z, Ge Y, Yang C, et al. Esophageal intraluminal baseline impedance is associated with severity of acid reflux and epithelial structural abnormalities in patients with gastroesophageal reflux disease. $J$ Gastroenterol. (2013) 48:601-10. doi: 10.1007/s00535-012-0689-6

16. de Bortoli N, Martinucci I, Savarino E, Tutuian R, Frazzoni M, Piaggi P, et al. Association between baseline impedance values and response proton pump inhibitors in patients with heartburn. Clin Gastroenterol Hepatol. (2015) 13:1082-8. doi: 10.1016/j.cgh.2014.11.035

17. Frazzoni M, Savarino E, de Bortoli N, Martinucci I, Furnari M, Frazzoni L, et al. Analyses of the post-reflux swallowinduced peristaltic wave index and nocturnal baseline impedance parameters increase the diagnostic yield of impedance-pH monitoring of patients with reflux disease. Clin Gastroenterol Hepatol. (2016) 14:40-6. doi: 10.1016/j.cgh. 2015.06.026

18. Farré R, Blondeau K, Clement D, Vicario M, Cardozo L, Vieth M, et al. Evaluation of oesophageal mucosa integrity by the intraluminal impedance technique. Gut. (2011) 60:885-92. doi: 10.1136/gut.2010.233049

19. Frazzoni M, Manta R, Mirante VG, Conigliaro R, Frazzoni L, Melotti G. Esophageal chemical clearance is impaired in gastroesophageal reflux diseasea $24 \mathrm{~h}$ impedance-pH monitoring assessment. Neurogastroenterol Motil. (2013) 25:399-e295. doi: 10.1111/nmo.12080

20. Frazzoni M, Bertani H, Manta R, Mirante VG, Frazzoni L, Conigliaro $\mathrm{R}$, et al. Impairment of chemical clearance is relevant to the pathogenesis of refractory reflux oesophagitis. Dig Liver Dis. (2014) 46:596-612. doi: 10.1016/j.dld.2014.03.005

21. Gyawali CP, Kahrilas PJ, Savarino E, Zerbib F, Mion F, Smout A, et al. Modern diagnosis of GERD: the Lyon Consensus. Gut. (2018) 67:135162. doi: 10.1136/gutjnl-2017-314722

22. Martinucci I, de Bortoli N, Savarino E, Piaggi P, Bellini M, Antonelli A, et al. Esophageal baseline impedance levels in patients with pathophysiological characteristics of functional heartburn. Neurogastroenterol Motil. (2014) 26:546-55. doi: 10.1111/nmo.12299

23. Frazzoni M, Penagini R, Frazzoni L, de Bortoli N, Mauro A, Tolone S, et al. Role of reflux in the pathogenesis of eosinophilic esophagitis: comprehensive appraisal with off- and on ppi impedance-ph monitoring. Am J Gastroenterol. (2019) 114:1606-13. doi: 10.14309/ajg.0000000000000379

24. Lin M, Gerson LB, Lascar R, Davila M, Triadafilopoulos G. Features of gastroesophageal reflux disease in women. Am J Gastroenterol. (2004) 99:1442-7. doi: 10.1111/j.1572-0241.2004.04147.x

25. Jaspersen D, Kulig M, Labenz J, Leodolter A, Lind T, Meyer-Sabellek W, et al. Prevalence of extra-oesophageal manifestations in gastro-oesophageal reflux disease: an analysis based on the ProGERD Study. Alim Pharm Therap. (2003) 17:1515-20. doi: 10.1046/j.1365-2036.2003.01606.x

26. Kessing BF, Bredenoord AJ, Weijenborg PW, Hemmink GJ, Loots CM, Smout AJ. Esophageal acid exposure decreases intraluminal baseline impedance levels. Am J Gastroenterol. (2011) 106:2093-7. doi: 10.1038/ajg.2011.276

27. Ye BX, Jiang LQ, Lin L, Wang Y, Wang M. Reflux episodes and esophageal impedance levels in patients with typical and atypical symptoms of gastroesophageal reflux disease. Medicine. (2017) 96:e7978. doi: 10.1097/MD.0000000000007978

28. El-Serag $\mathrm{H}$, Becher A, Jones R. Systematic review: persistent reflux symptoms on proton pump inhibitor therapy in primary care and community studies. Aliment Pharmacol Ther. (2010) 32:720-37. doi: 10.1111/j.1365-2036.2010.04406.x

29. Ruigómez A, Johansson S, Wernersson B, Fernández Cantero O, García Rodríguez LA. Gastroesophageal reflux disease in primary care: using changes in proton pump inhibitor therapy as an indicator of partial response. Scand J Gastroenterol. (2012) 47:751-61. doi: 10.3109/00365521.2012.679682

30. Bytzer P, van Zanten SV, Mattsson H, Wernersson B. Partial symptom response to proton pump inhibitors in patients with non-erosive reflux disease or reflux oesophagitis-a post hoc analysis of 5796 patients. Aliment Pharmacol Ther. (2012) 36:635-43. doi: 10.1111/apt.12007

31. Lundell L, Hatlebakk J, Galmiche JP, Attwood SE, Ell C, Fiocca R, et al. Long-term effect on symptoms and quality of life of maintenance therapy with esomeprazole $20 \mathrm{mg}$ daily: a post hoc analysis of the LOTUS trial. Curr Med Res Opin. (2015) 31:65-73. doi: 10.1185/03007995.2014. 980500

32. Martinucci I, Savarino EV, Pandolfino JE, Russo S, Bellini M, Tolone S, et al. Vigor of peristalsis during multiple rapid swallows is inversely correlated with acid exposure time in patients with NERD. Neurogastroenterol Motil. (2016) 28:243-50. doi: 10.1111/nmo.12719

33. Zia JK, Heitkemper MM. Upper gastrointestinal tract motility disorders in women, gastroparesis, and gastroesophageal reflux disease. Gastroenterol Clin North Am. (2016) 45:239-51. doi: 10.1016/j.gtc.2016. 02.003

34. Vega KJ, Palacio C, Langford-Legg T, Watts J, Jamal MM. Gender variation in oesophageal motor function: analysis of 129 healthy individuals. Dig Liver Dis. (2010) 42:482-4. doi: 10.1016/j.dld.2009.11.009

35. Grande L, Lacima G, Ros E, Pera M, Ascaso C, Visa J, et al. Deterioration of esophageal motility with age: a manometric study of 79 healthy subjects. 
Am J Gastroenterol. (1999) 94:1795-801. doi: 10.1111/j.1572-0241.1999. 01208.x

36. Masaka T, Iijima K, Endo H, Asanuma K, Ara N, Ishiyama F, et al. Gender differences in oesophageal mucosal injury in a reflux oesophagitis model of rats. Gut. (2013) 62:6-14. doi: 10.1136/gutjnl-2011-301389

37. Torihata Y, Asanuma K, Iijima K, Mikami T, Hamada S, Asano N, et al. Estrogen-Dependent Nrf2 expression protects against refux-induced esophagitis. Dig Dis Sci. (2018) 63:345-55. doi: 10.1007/s10620-017-4885-3

38. Honda J, Iijima K, Asanuma K, Ara N, Shiroki T, Kondo Y, et al. Estrogen Enhances Esophageal Barrier Function by Potentiating Occludin Expression. Dig Dis Sci. (2016) 61:1028-38. doi: 10.1007/s10620-015-3980-6

39. Menon S, Nightingale P, Trudgill N. Is hormone replacement therapy in post-menopausal women associated with a reduced risk of oesophageal cancer? United European Gastroenterol J. (2014) 2:374-82. doi: $10.1177 / 2050640614543736$
40. Jacobson BC, Moy B, Colditz GA, Fuchs CS. Postmenopausal hormone use and symptoms of gastroesophageal reflux. Arch Intern Med. (2008) 168:1798804. doi: 10.1001/archinte.168.16.1798

Conflict of Interest: The authors declare that the research was conducted in the absence of any commercial or financial relationships that could be construed as a potential conflict of interest.

Copyright $\odot 2021$ Ye, Wang, Lin, Jiang and Wang. This is an open-access article distributed under the terms of the Creative Commons Attribution License (CC BY). The use, distribution or reproduction in other forums is permitted, provided the original author(s) and the copyright owner(s) are credited and that the original publication in this journal is cited, in accordance with accepted academic practice. No use, distribution or reproduction is permitted which does not comply with these terms. 